\title{
Measurement of stroke volume from pulmonary artery pressure record in man
}

\author{
A. A. Zacharoulis, ${ }^{1,2}$ T. R. Evans, G. M. Ziady, D. J. Coltart, ${ }^{3}$ and J. P. Shillingford \\ From The Cardiovascular Research Unit, Royal Postgraduate Medical School, Hammersmith Hospital, London
}

Stroke volume was determined from the pulmonary artery pressure record by application of the pulse contour method. Pulmonary artery pressure records were obtained in 17 patients using a high fidelity catheter-tip pressure transducer and simultaneous measurements of cardiac output were obtained from indicator dilution curves. The formula used was $S V=K P_{\mathrm{sa}}\left(I+T_{\mathrm{s}} / T_{\mathrm{d}}\right)$ where $P_{\mathrm{sa}}$ is the planimetered area beneath the systolic portion of the pulmonary artery pressure curve. $T_{\mathrm{s}}$ and $T_{\mathrm{d}}$ are the durations of systole and diastole, and $K$ is a constant.

Stroke volume was altered by isometric handgrip exercise and/or pharmacological agents in I5 patients. Serial measurements were made in 2 patients in acute pulmonary oedema after myocardial infarction.

Comparison of a wide range of values of stroke volume by the pulse contour method with those obtained from dye dilution curves showed a good correlation $(r+0.97, P<0.001)$ regression line $y=I \cdot 01 x-0.47$.

Measurement of stroke volume from the pulmonary artery pressure contour is a technique of potential value in serial haemodynamic monitoring.

The need for a simple, safe reproducible method of determining stroke volume had become more apparent with increasing numbers of patients being treated in medical and surgical intensive care units. Fick and indicator dilution methods are inconvenient to perform repeatedly in critically ill patients. Moreover, both of the preceding methods and also thermodilution, though adequate for estimation of cardiac output in man during steady state conditions, are unable to follow rapid, beat-tobeat changes in stroke volume. In consequence we sought to find a more clinically acceptable method to monitor the output of the heart.

Frank (1930) aroused interest in the pulse contour method for determining stroke volume. Various modifications of the original method were employed but the results were generally unsatisfactory. Warner et al. (1953) restored interest in the method by introducing a calibrating factor allowing for individual variation in elasticity and diastolic size of aorta and large arteries. This involved an initial measurement of cardiac output by an independent

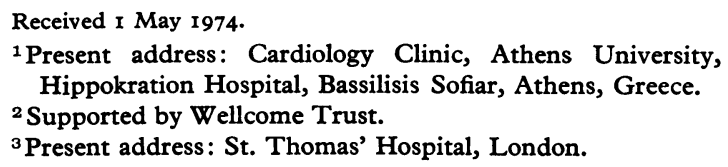

method such as the Fick or indicator dilution procedure in order to determine the calibration factor. These methods have been applied to the systemic side of the circulation but Zacharoulis et al. (1974) using a high fidelity catheter tip transducer (Millar and Baker, 1973) have shown that it is possible to apply one of Warner's formulae (Warner et al., 1953) to the pulmonary circulation in dogs. The results were encouraging enough to suggest that the method should be evaluated in man.

The technique was studied in patients undergoing diagnostic cardiac catheterization and also in patients being monitored haemodynamically after acute myocardial infarction. It is the purpose of this study to evaluate the relation between stroke volume determined by pulmonary artery pulsecontour method, with stroke volume simultaneously measured from indicator dilution curves.

\section{Patients and methods}

Fifteen patients ( 12 men and 3 women) were studied during routine diagnostic catheterization. The diagnoses are listed in Table $\mathrm{r}$. A No. $5 \mathrm{~F}$ or No. $7 \mathrm{~F}$ Millar pressure tip transducer was introduced via an antecubital vein into the main pulmonary artery using fluoroscopy. The Millar catheter was used in order to obtain a high quality record virtually free of artefacts. The pulmonary artery pressure trace was recorded either on a 7788 A Hewlett- 
TABLE I

\begin{tabular}{lll}
\hline $\begin{array}{l}\text { No. of } \\
\text { patients }\end{array}$ & Diagnosis & Rhythm \\
\hline 7 & Mitral incompetence & $\begin{array}{l}\text { 5 atrial fibrillation } \\
\text { 2 sinus rhythm }\end{array}$ \\
4 & $\begin{array}{c}\text { Hypertrophic cardiomyo- } \\
\text { pathy }\end{array}$ & Sinus rhythm \\
I & $\begin{array}{c}\text { Congestive cardiomyo- } \\
\text { pathy } \\
\text { Ischaemic heart disease }\end{array}$ & $\begin{array}{l}\text { Sinus rhythm } \\
\text { Sinus rhythm }\end{array}$ \\
\hline
\end{tabular}

Packard recorder at a paper speed of $100 \mathrm{~mm} / \mathrm{sec}$ or on the Electronics for Medicine DR8 recorder at a paper speed of $200 \mathrm{~mm} / \mathrm{sec}$. Using the integral high-pass filter incorporated into the Millar catheter system the heart sounds were recorded on a separate channel. Cardiac output was measured by the dye dilution technique using indocyanine green and a modified Gilford densitometer, the original cuvette being replaced by a disposable plastic cuvette of smaller volume. Dye was injected into the right atrium via a $5 \mathrm{~F}$ Cournand catheter when the $5 \mathrm{~F}$ Millar was used but into the main pulmonary artery when the $7 \mathrm{~F}$ Millar with a side hole was used. Sampling was from the left heart catheter. The instrument was calibrated with known standard dye concentrations. Measurements of stroke volume by the dye dilution and pulse-contour methods were made in the resting supine state and after the haemodynamic state was altered by one of the following interventions.

\section{Handgrip exercise}

Thirteen patients performed isometric handgrip exercise maintaining a pressure of $0.3 \mathrm{~kg} / \mathrm{cm}^{2}$ for 2 to $3 \mathrm{~min}$ utes. This produced a mean increase of cardiac output of 12 per cent (range $-5 \%$ to $49 \%$ ) and a mean decrease in stroke volume of 6 per cent, with a range of $(-3 \%$ to $-25 \%$ ). The average heart rate was increased from 84 beats/min to IOI beats $/ \mathrm{min}$.

\section{Pharmacological agents}

Isoprenaline was administered as either a bolus of 5 to Io $\mu \mathrm{g}$ (in 3 patients) or as an infusion of $\mathrm{I}$ to $2 \mu \mathrm{g} / \mathrm{min}$ (in 2 patients). Infusions of dobutamine $2.5,5$, and 10 $\mu \mathrm{g} / \mathrm{kg}$ per min were given to another patient. Dobutamine is a new inotropic agent showing dissociation of positive chronotropic and inotropic effects (Akhtar, Chaudhry, and Cohn, 1973). Ouabain $0.5 \mathrm{mg}$ intravenously and glyceryl trinitrate $0.5 \mathrm{mg}$ sublingually were given to one patient and another received practolol $0.3 \mathrm{mg} / \mathrm{kg}$ intravenously. These drugs produced a mean increase of cardiac output of 33 per cent (range - $15 \%$ to $103 \%$ ) and a mean increase in stroke volume of 19 per cent (range $-6.4 \%$ to $58.5 \%$ ). The cumulative average heart rate increased from 77 beats/min to 86 beats/min.

\section{Serial measurements}

Two male patients with acute myocardial infarction, who were in left ventricular failure, were studied in the coronary care unit. The procedure was fully explained to them and their consent was obtained. A $5 \mathrm{~F}$ Millar catheter was introduced into the main pulmonary artery and dye injected into the right atrium via a $24^{\prime \prime}$ Bardic Intracath. Arterial blood was sampled via a No. 18 Medicut (Argyle) inserted into either the brachial or radial artery. Recordings were made on a $7788 \mathrm{~A}$ HewlettPackard recorder at a paper speed of $100 \mathrm{~mm} / \mathrm{sec}$ and the modified Gilford densitometer was used as before. In one patient measurements were made on the first, third, and fifth days after admission and in the other on the first and third days. The densitometer was calibrated after each set of measurements. The Millar catheter was left in the pulmonary artery for routine haemodynamic monitoring.

\section{Calculations}

Dye dilution method Cardiac output was measured from the dye curves by the Hamilton method of extrapolation and summation of the curves at one second intervals. Average stroke volume was determined by dividing the cardiac output by the heart rate.

Pulse contour method Stroke volume was measured from the pulse contour method using the equation:

$$
S V=K P_{s a}\left(I+T_{s} / T_{d}\right) \text {, }
$$

where $\mathrm{SV}=$ stroke volume in $\mathrm{ml}$

$$
\mathrm{K}=\text { constant }
$$

$\mathbf{P}_{\mathbf{s d}}=$ planimetered area beneath the systolic portion of the pulmonary artery pressure curve. The area was delineated by drawing a horizontal line from the preceding end-diastolic pressure level and a second line vertically through the first high frequency component of the pulmonary second sound (Fig. I).

$T_{s}=$ duration of systole in milliseconds

$T_{d}=$ duration of diastole in milliseconds

The constant $\mathrm{K}$ was calculated by substituting the stroke volume (SV) obtained from the dye dilution method into the formula given above. Eight consecutive pulmonary artery contours recorded during the build up of the dye curve were analysed for the planimetered area $\left(\mathbf{P}_{\mathbf{s a}}\right)$ and $T_{s} / T_{d}$ fraction and the mean value obtained used to calculate the constant $\mathrm{K}$; observations were made during continuing respiration. Two or three initial dye curves were recorded and two or three values for the constant $\mathrm{K}$ were calculated. The mean value of $\mathrm{K}$ was used for the subsequent calculations of stroke volume from the pulse contour method. The mean constant $\mathrm{K}$ was derived from determinations in the resting supine state and in those patients with acute myocardial infarction from measurements made on the first day. Stroke volumes derived from pulse contour method during the different haemodynamic situations were compared with the stroke volumes obtained from simultaneous dye curves.

\section{Results}

Mean values for stroke volume, cardiac output, and heart rate for the patients who did this handgrip 


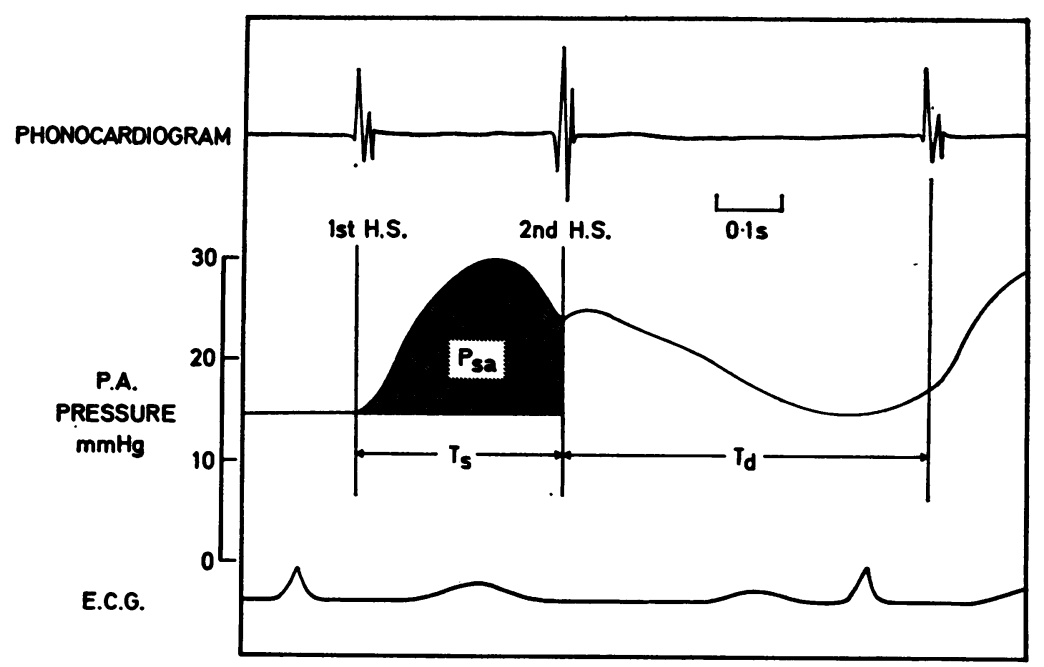

FI G. I Record of pulmonary artery pressure, phonocardiogram, and electrocardiogram. The area $P_{\mathrm{sa}}$ is the area under the pulmonary artery pressure curve, above the lowest level achieved in the preceding diastole and the duration of systole. $T_{\mathrm{s}}=$ duration of systole and $T_{\mathrm{d}}=$ duration of diastole.

TABLE 2 Heart rate, stroke volume, and cardiac ouput obtained during varying haemodynamic conditions $($ mean $\pm S E M)$

\begin{tabular}{|c|c|c|c|c|c|c|}
\hline \multirow[t]{2}{*}{ Intervention } & \multicolumn{2}{|l|}{$\begin{array}{l}\text { Heart rate } \\
\text { (beats/min) }\end{array}$} & \multicolumn{2}{|c|}{ Stroke volume $(\mathrm{ml})$} & \multicolumn{2}{|c|}{ Cardiac output (l./min) } \\
\hline & Control & Effect & Control & Effect & Control & Effect \\
\hline \multirow[t]{2}{*}{ Handgrip exercise } & $\begin{array}{l}84 \cdot 01 \\
\pm 5.4\end{array}$ & $\begin{array}{l}\text { IOI.2 } \\
\pm 7 \cdot 0\end{array}$ & $\begin{array}{c}56 \cdot 93 \\
\pm 5 \cdot 3\end{array}$ & $\begin{array}{l}52 \cdot 38 \\
\pm 5 \cdot 4\end{array}$ & $\begin{aligned} & 4.58 \\
\pm & 0.3\end{aligned}$ & $\begin{aligned} & 5.11 \\
\pm & 0.4\end{aligned}$ \\
\hline & First day & Third day & First day & Third day & First day & Third day \\
\hline \multirow[t]{2}{*}{ Monitored patients } & $\begin{array}{r}98 \cdot 27 \\
\pm 2 \cdot 7\end{array}$ & $\begin{array}{l}91 \cdot 62 \\
\pm 0.6\end{array}$ & $\begin{array}{l}29 \cdot 69 \\
\pm 1 \cdot 2\end{array}$ & $\begin{array}{l}38 \cdot 31 \\
\pm I \cdot 2\end{array}$ & $\begin{array}{r}2.90 \\
\pm 0.06\end{array}$ & $\begin{array}{r}3.5 \\
\pm 0.1\end{array}$ \\
\hline & & $\begin{array}{l}\text { Fifth day } \\
86.03 \\
\pm 0.2\end{array}$ & & $\begin{array}{c}\text { Fifth day } \\
43.08 \\
\pm \mathrm{I} \cdot 8\end{array}$ & & $\begin{array}{c}\text { Fifth day } \\
3.7 \\
\pm 0 \cdot 15\end{array}$ \\
\hline
\end{tabular}

TABLE 3 Statistical information

\begin{tabular}{|c|c|c|c|c|c|c|c|}
\hline Intervention & $\begin{array}{l}\text { No. of } \\
\text { determina- } \\
\text { tions }\end{array}$ & Slope & Intercept & $\begin{array}{l}\text { Mean stroke } \\
\text { volume ( } \mathrm{ml}) \\
\text { indicator- } \\
\text { dilution } \\
\text { curves }\end{array}$ & $\begin{array}{l}\text { Mean stroke } \\
\text { volume ( } m l) \\
\text { contour } \\
\text { method }\end{array}$ & ' $r$ ' & $\begin{array}{l}\text { Two-tail } \\
\text { test for } \\
\text { significance } \\
\text { of ' } r \text { ' }\end{array}$ \\
\hline $\begin{array}{l}\text { Handgrip exercise } \\
\text { Pharmacological agents } \\
\text { Combined data handgrip } \\
\text { exercise, pharmaco- } \\
\text { logical agents and } \\
\text { infarctions }\end{array}$ & $\begin{array}{l}13 \\
16\end{array}$ & $\begin{array}{l}I \cdot 02 \\
I \cdot 02\end{array}$ & $\begin{array}{l}+1 \cdot 45 \\
-2 \cdot 14\end{array}$ & $\begin{array}{l}52 \cdot 40 \\
77 \cdot 00\end{array}$ & $\begin{array}{l}54 \cdot 90 \\
76 \cdot 40\end{array}$ & $\begin{array}{l}0.969 \\
0.967\end{array}$ & $\begin{array}{l}\mathbf{P}<0.001 \\
\mathbf{P}<0.001\end{array}$ \\
\hline
\end{tabular}




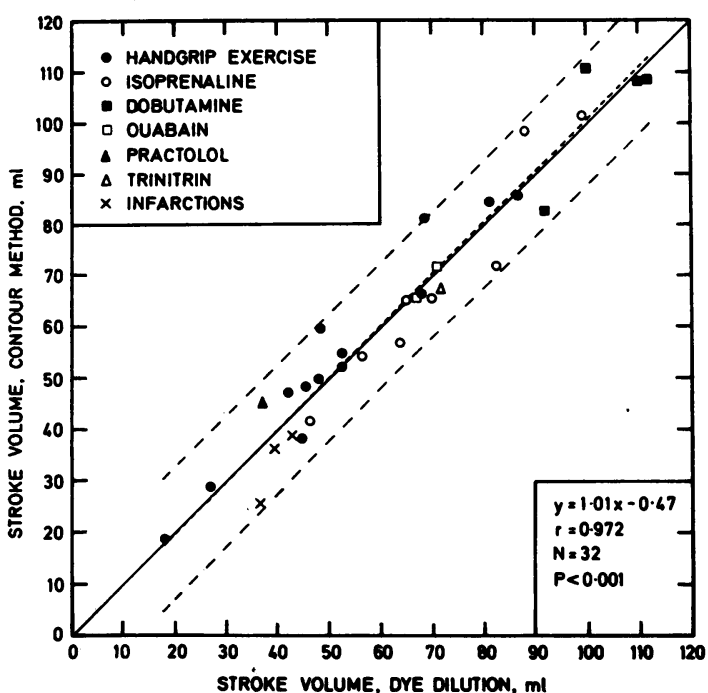

FIG. 2 Comparison of stroke volume estimated by pulmonary artery pressure contour method with stroke volume measured from dye dilution curves. Changes in stroke volume were produced by isometric handgrip exercise, pharmacological manoeuvres, and during the treatment of acute pulmonary oedema. The continuous line is the line of identity, the dashed line is the regression line for all data points and the 95 per cent confidence limits are shown.

exercise and the monitored patients in the resting supine state and during the interventions are presented in Table 2. Data for the mean stroke volume during handgrip exercise, pharmacological agents, and after myocardial infarction as calculated by the pulse contour method are plotted against mean stroke volume derived from the indicator dilution curves (Fig. 2). The regression line $(y=1 \cdot 01 x-0.47)$ was close to the line of identity. The correlation coefficient was $r=+0.97(P<0.00 I)$. In the group of patients given various pharmacological agents the values calculated from the pulse contours followed the changes shown by the indicator dilution method whatever the direction of the magnitude of the change.

Fig. 3 shows the regression line of stroke volume calculated by pulse contour method compared with those measured by indicator dilution curves for individual data obtained during handgrip exercise and during administration of pharmacological agents. Both of the regression lines are close to the identity line and the slopes and intercepts are not significantly different. Additional statistical information is shown in Table 3.

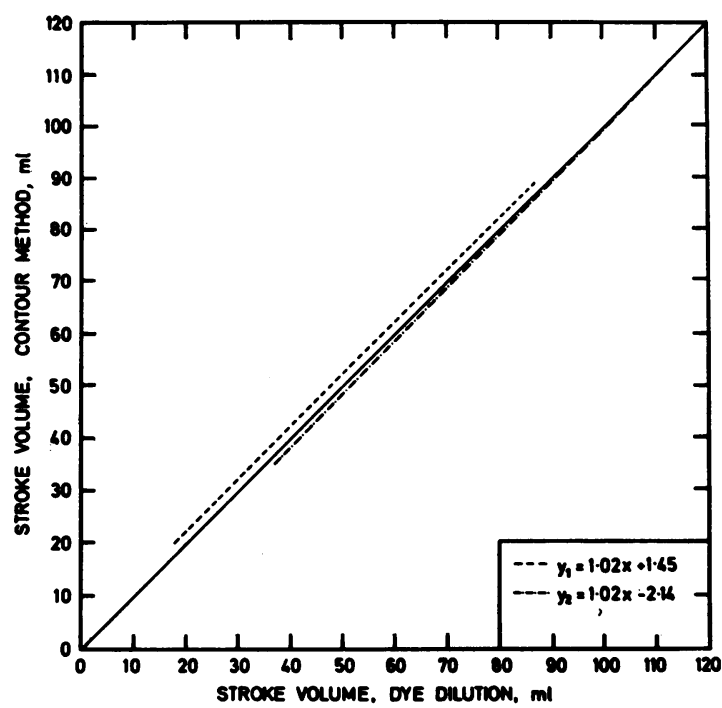

FI G. 3 Individual regression lines for data obtained either during isometric handgrip exercise or during the administration of pharmacological agents. The continuous line is the line of identity; the dashed line represents the regression line for data from handgrip exercise $(y I)$, and the stippled line for data from pharmacological agents (y2).

\section{Discussion}

The original 'Windkessel' model proposed by Otto Frank (1930) for measuring cardiac output from systemic arterial pulse contours did not make adequate allowance for changes in arterial pulse contours in arterial impedance associated with distensibility and resistance which occur in differing pathological states. Warner et al. (1953) overcame some of these difficulties by introducing an indirect method of calibrating pulse contour derived stroke volume, by introducing a constant for each individual patient. The constant reflected the particular characteristics of a patient's arterial system and enabled stroke volume to be calculated with acceptable accuracy. Warner (1966) and Warner, Gardner, and Toronto (1968) demonstrated accurate reproducibility of stroke volume measurements during various interventions both in dog and man. Kouchoukos, Sheppard, and McDonald (1970) evaluated in dogs one of the formulae proposed by Warner et al. (1953) for use in the systemic circulation, and found a good correlation $(r=+0.93$ to 0.99$)$ between stroke volume determined by electromagnetic flowmeter and pulse contour method. However, this close relation was reduced when catecholamines were administered. A separate study by the same authors Kouchoukos et al. 
(1969) in postoperative patients showed a poor correlation over a 48 -hour period between the stroke volume derived from pulse contour and that obtained by indicator dilution method. Alderman et al. (1972) compared stroke volumes measured by an indicator-dilution technique with the values obtained by several pulse contour methods, and concluded that these methods had a potentially useful role in the monitoring of critically ill patients. More recently, Starmer et al. (1973) studied stroke volumes measured with an electromagnetic flowmeter and several pulse contour methods during multiple interventions in dog and man. These authors found that though pulse contour methods of estimating stroke volume may function accurately over a wide range of values when alterations were produced by a single agent or manoeuvre, none of the methods was adequately consistent when alterations were induced by more than one factor. Thus, they believed the clinical application of the methods was very limited.

To our knowledge, the pulse contour method for calculating stroke volume has only been applied in man on the systemic side of the circulation. Zacharoulis et al. (1974) showed in dogs that it was possible to apply the formula which Kouchoukos (Kouchoukos et al., 1969, 1970) had used to the pulmonary artery pressure pulse contour. This study compared stroke volume determined by an electromagnetic flowmeter with stroke volume estimated from the pulmonary artery pressure contour and showed a good correlation $(r=+0.97-0.99)$ during various pharmacological and other interventions. However, this relation did not hold when saline was rapidly infused in an attempt to produce acute pulmonary oedema. The error under these circumstances might be thought to be potentially serious in regard to the application of the method in man. The amount of saline injected into the dogs was grossly unphysiological and in practice a close correlation still existed when measurements were obtained in patients with acute myocardial infarction with pulmonary oedema.

With the already widespread use of pulmonary artery pressure monitoring in intensive care units, the ability to use the pulmonary pressure trace to calculate stroke volume would be an additional benefit. Using a conventional fluid-filled catheter and transducer the pulmonary trace is often unsuitable for pulse contour analysis because of artefacts. The high fidelity Millar catheter produces a tracing free of artefact, enabling planimetry of pulse contour area to be accurate and reproducible. Once the constant $\mathrm{K}$ has been established by an initial measurement of cardiac output, stroke volume can be serially monitored.
The results indicate that stroke volume estimated from pulmonary artery pressure contour correlate closely with stroke volume determined by dye dilution procedures during different interventions. Isometric handgrip produced only moderate changes in stroke volume, whereas pharmacological agents produced more pronounced changes. It is well recognized that duplicate determinations of cardiac output may vary by as much as 12 to 20 per cent (Stenson, Crouse, and Harrison, 1972).

The close correlation between stroke volume measured by the pulmonary artery pressure contour method and indicator dilution curves in this study may well reflect the fact that simultaneous and not serial cardiac output, which may change, was measured.

The measurement of stroke volume from the pulmonary artery pressure contour is a technique of potential value in serial haemodynamic monitoring. Computerization will enable instantaneous measurements to be obtained. It has been shown to be safe, reproducible, technically simple to institute, and worthy of further clinical evaluation.

The authors wish to thank Mr. G. Rainbow, Mrs. P. Sym, and Miss E. Callowhill for skilled technical assistance.

\section{References}

Akhtar, N., Chaudhry, M. H., and Cohn, J. N. (1973). Dobutamine: selective inotropic action in patients with heart failure. Circulation, 48, Suppl. IV, 136.

Alderman, E. L., Branzi, A., Sanders, W., Brown, B. W., and Harrison, D. C. (1972). Evaluation of the pulse-contour method of determining stroke volume in man. Circulation, $46,546$.

Frank, O. (1930). Schätzung des Schlagvolumens des menschlichen Herzens aud Grund der Wellen- und Windkesseltheorie. Zeitschrift für Biologie, 90, 405.

Kouchoukos, N. T., Sheppard, L. C., and McDonald, D. A. (1970). Estimation of stroke volume in the dog by a pulse contour method. Circulation Research, 26, 6II.

Kouchoukos, N. T., Sheppard, L. C., McDonald, D. A., and Kirklin, J. W. (1969). Estimations of stroke volume from the central arterial pressure contour in postoperative patients. Surgical Forum, 20, 180.

Millar, H. D., and Baker, L. E. (1973). A stable ultraminiature catheter-tip pressure transducer. Medical and Biological Engineering, 11, 86.

Starmer, C. F., McHale, P. A., Cobb, F. R., and Greenfield, J. C. (1973). Evaluation of several methods for computing stroke volume from central aortic pressure. Circulation Research, 33, 139.

Stenson, R., Crouse, L., and Harrison, D. C. (1972). Computer measurement of cardiac output by dye dilution: comparison of computer, Fick, and Dow techniques. Cardiovascular Research, 6, 449.

Warner, H. R. (I966). Role of computers in medical research. fournal of the American Medical Association, 196, 944.

Warner, H. R., Gardner, R. M., and Toronto, A. F. (I968). Computer-based monitoring of cardiovascular functions in postoperative patients. Circulation, 37 and 38, Suppl. II, 68. 
Warner, H. R., Swan, H. J. C., Connolly, D. C., Tompkins, R. G., and Wood, E. H. (1953). Quantitation of beat-tobeat changes in stroke volume from the aortic pulse contour in man. Fournal of Applied Physiology, 5, 495.

Zacharoulis, A. A., Mills, C. J., Gabe, I. T., and Shillingford, J. P. (1974). Estimation of stroke volume from the pul- monary artery pressure record. Cardiovascular Research, 8, 506.

Requests for reprints to Professor J. P. Shillingford, The Cardiovascular Research Unit, Royal Postgraduate Medical School, Hammersmith Hospital, London WI2 OHS. 